\title{
KEY DETERMINANTS AND EFFECT OF ORGANIZATIONAL COMMITMENT ON EMPLOYEE'S INTENTION TO STAY: A PLS-SEM APPROACH
}

\author{
Nguyen Ngoc Duy Phuong \\ School of Business, International University, Vietnam National University; phuongnida@gmail.com \\ Le Thi Huyen Trang \\ School of Business, International University, Vietnam National University
}

\begin{abstract}
Employee retention always plays a vital role for all organization's success, especially for auditing firms which human cost occupies the largest portion. With the specific experience and skills, professional staff of auditing firms have a lot of opportunities to change their working place. Their leaving will bring about unrecoverable costs on orientation and training as well as incur cost for new staff. Furthermore, the morale of remaining staff will be also affected. Therefore, it is essential to understand the factors affecting employee's intention to stay. This study investigates the relationships of emotional exhaustion, compensation and benefit, promotion opportunity, co-worker relationship, supervisor support, leadership and organizational commitment to employee's intention to stay. In addition, the mediating effect of organizational commitment is also examined. The research applies quantitative method and survey by questionnaires from 256 usable respondents. The collected data is then processed by SmartPls 3.0. The results show that intention to stay of employees working at bigfour auditing companies in Ho Chi Minh City is impacted by emotional exhaustion and organizational commitment, in which the latter itself is influenced by emotional exhaustion, compensation and benefits, promotion opportunity, co-worker relationship and leadership. This research shows critical contribution for the research field of employee's intention to stay as well as provides recommendations for the employee retention strategies of big-four auditing firms in Vietnam.
\end{abstract}

Keywords: employee's intention to stay, organizational commitment, big-four auditing firms

\section{Introduction}

The big-four is widely known as the top four largest auditing firms in the world. The big-four's services include accounting and auditing, taxation, management and business consulting together with risk assessment and control. Members of this group are KPMG, PwC, EY and Deloitte. Established and operated in Vietnam from the beginning of 1990s, the Big Four lead the top ten auditing firms which have the highest turnover according to the report of Vietnam Association of Certified Public Accountants (VACPA). Each company has around 600 to 700 employees working across Vietnam. Cost from human resource also make up the largest portion of total operating cost of these companies. Obviously, like any organizations, human resource is heart of the big-four auditing firms. With the development of economy as well as society, there are a lot of opportunities for employees to switch their current works. Nowadays, all organization consider employee retention as their most essential objective since recruitment of qualified candidate is crucial but their retention is much more imperative. Organizations must spend a huge amount on orientation and training for new employees while the same cost of resigned employees cannot be recovered. Furthermore, the knowledge and skills of employees are valuable assets of any organization. Losing skilled employees and starting to recruit and train new ones is not always a cost-effective situation. All organizations want to reduce employee turnover to acceptable point so that they can avoid wasting a huge amount of money. Clearly, employee turnover causes cost by both direct and indirect ways. The direct cost comes from reinstatement, recruitment, expenses of temporary staff and wasted time. Indirect cost forms by decrease in employee's attitude, extra pressure on remaining employees, and decrease of quality of product/service, learning costs, and the lost expertise from the organization (Beardwell and Thompson, 
2014). The employee turnover also creates negative influence on the organization's performance if the management cannot be fully aware and manage. Finally, decision of leave of one employee may cause pressure and bad emotional effect to the remaining employees since they may feel stressful about the workload or think that the company may in unstable status. Given the above, understanding the factors affecting employee's intention to stay is essential for any organizations, especially organizations with high cost of human resources like auditing firms, for their strategy on human resources.

\section{Literature review}

The root of employee's intention to stay is social exchange theory which was built up by Thibaut and Kelley (1959). The theory clarifies the logic why people have relationships with each other and specified the suitable time for beginning and ending of the relationships. It also highlighted that personal relationships are along with its costs and rewards (Mustapha et al. 2010). According to Blau's argument (1964), the theory supposes that good deeds should be paid back. Mossholder, Settoon and Henagan (2005) learned that when people receive benefits from others, they would later feel responsible and then repay through effort and loyalty. Mustapha et al. (2010) states that effort and loyalty appear as signs of job commitment and intense tendency to stick with the current organization. This constructive mental reaction will make employees have tendency to be more attached and devoted to the organization and give up the intention to find new job (Bunderson, 2001, Coyle-Shapiro and Kessler, 2000). In other works, employees are committed to organization due to responsibility and benefits received from it. Specifically, intention to stay appears at the time such responsibility arise (Rhoades and Eisenberger, 2002).

Employees facing high-level emotional exhaustion have difficulty in psychologically associate with surrounding environment (Alarcon, 2011). Therefore, they are short of motivation and aspiration to maintain their involvement in work activities, which followed by lower intention to stay with the current organization (Maslach et al., 2001). Alarcon (2011) performs a meta-analysis to manifest that employees facing high-level emotional exhaustion show low tendency to stay than those have lowlevel emotional exhaustion. Organizational commitment is also detected as contradictory with emotional exhaustion by Azeem (2010). Some studies also suggest that emotional exhaustion negatively affect individual's behavior and then resulted to adverse outcome such as decreasing job performance, job association and commitment and inflating aim of leaving (Jackson and Maslach, 1982; Leiter and Maslach, 1988; Motowidlo and Packard, 1986; Shirom, 1989; Wright and Bonett, 1997; Wright and Cropanzano, 1998). We propose:

H1: The emotional exhaustion exerts negative (-) effect on organizational commitment.

$\mathrm{H} 2$ : The emotional exhaustion exerts negative (-) effect on employee's intention to stay.

According to Millers and Wheeler (1992), compensation and benefits is one of reasons to keep an employee to stay at an organization. Talented employee trends to be highly paid to deserve with their ability. (Shepherd and Mathews, 2000; Jardine and Amig, 2001). Johari et al. (2012) perform research to explore the relationship of training and development, career development, compensation and benefits, performance appraisal and achievement to employee's retention tendency. The results show that compensation and benefit correlates significantly with intention to stay of target workers. Regarding organizational commitment, Steers (1998) show that compensation has a significant effect on organizational commitment. Therefore, it can be assumed that:

H3: Compensation and benefits exerts positive $(+)$ effect on organizational commitment.

H4: Compensation and benefits exerts positive $(+)$ effect on employee's intention to stay.

Wan, Sulaiman \& Omar (2012) state that the fairer promotion opportunities are, the more committed employees feel to the organization. Companies are recommended to provide promotional opportunities for their employees to raise their organizational commitment level (Amiria, et al, 2010; Siew et al,2011; Foumany et al, 2012). The fair promotion also reduces leaving intention of employees. As such, the below hypotheses are proposed:

H5: Promotion opportunity exerts positive $(+)$ effect on organizational commitment.

H6: Promotion opportunity exerts positive $(+)$ effect on employee's intention to stay.

Positive coworker relationships appear tobe connected with reduced job stress, strain, or burnout (Beehr, Jex, Stacy, \& Murray, 2000; Fry \& Barker, 2002; Hepburn, Loughlin, \& Barling, 1997; 
Johnson \& Hall, 1988; Koeske \& Koeske, 1989;), higher job satisfaction (Ducharme \& Martin, 2000; Hurlbert, 1991; Nielsen et al., 2000; Roxburgh, 1999), reduced turnover intentions and higher commitment (Nielson et al., 2000). Thus, the researcher would like to propose the followings:

H7: Co-worker relationship exerts positive $(+)$ effect on organizational commitment.

H8: Co-worker relationship exerts a positive $(+)$ effect on employee's intention to stay.

Casper, Harris, Taylor \& Wayne (2011) affirm that support from bosses to their employees may enhance affective commitment and job satisfaction. Supervisor support makes employee highly committed to the organization by their satisfaction with job and motivation. In addition, Johnston, Parasuraman, Futrell and Black (1990) judge that considerate leaders make employees stay longer with the organization than inconsiderate ones. Vandenberghe and Bentein's research (2009) shows that supervisor support adversely constructed to turnover intention. Therefore, they are postulated that:

H9: Supervisor support exerts positive $(+)$ effect on organizational commitment. H10: Supervisor support exerts positive $(+)$ effect on employee's intention to stay.

In McNeese-Smith (1995)'s study, he discovers that leadership has a strongly constructive relationship with job satisfaction and organizational commitment of employees. Bread (2007) claims that the leaving intention depends more on human factor - leadership than organization. Studer (2004) conducts research and confirms that the main reason to make employees leave the association is their dissatisfied leaders. Similarly, according to Ferreira (2007) cited in Micha el (2008), the relationship between an employee and immediate manager decides employee's staying intention in an organization. Moreover, inefficient leadership can lead to weak employee performance, high stress, low job commitment and increase turnover (Gwavuya, 2011). Therefore, it can be assumed that:

H11: Leadership exerts positive (+) effect on the organizational commitment.

H12: Leadership exerts positive $(+)$ effect on the employee's intention to stay.

In the research on correlations among job satisfaction, organizational commitment and intention to stay of United States Air Force Certified Registered Nurse Anesthetists, Chaney (1991) confirms that the commitment to organization and retention intention are somewhat constructively correlated. Stairs \& Galpin (2010) declared that higher levels of engagement lead to lower absenteeism and higher stay intention. When organizational commitment rises, it positively impacts intention to stay (Nawab \& Bhatti, 2011). Nasyira, Othman and Ghazali (2014) also recommen that there is a certain connection between organizational commitment and employee's staying tendency. Hence, the hypothesis below is proposed:

H13: Organizational commitment exerts positive $(+)$ effect on employee's intention to stay.

\section{Research Methodology}

To ensure content validity, the measurement scale of this research is adapted from previous studies. The researcher also customizes some questions to make the questionnaire updated to the study. Employee's intention to stay s is adopted from scale of Kalbers \& Cenker (2007). Organizational commitment is employed from Organizational Commitment Questionnaire of Mowday, Steers \& Porter (1979). Emotional exhaustion is based on the research of Fletcher, Alfes \& Robinson (2016). Next, compensation and benefit uses six items from the study of Moyes, Cortes \& Lin (2007). The scale of promotion opportunity is combined from researches of Bigliardi, Petroni \& Dormio (2005) and Gathungu, Iravo \& Namusonge (2015). Co-worker relationship is adopted from studies of Hain (2005) while supervisor support is based on studies of Eisenberger (1986) and Soulen (2003). Lastly, leadership's scale is developed from the scale of Chitra (2013).

The target population of this study comprises employees who are currently working at big-four auditing firms for more than 6 months. The four companies include KPMG, Deloitte, PwC and EY. Due to time and resource strains, convenience sampling technique was used for this study. After sample is determined, the researcher decides to use questionnaire to obtain the data. For ease of data collection, the questionnaires are translated into Vietnamese. Questionnaires are printed and delivered by hand to correspondents working at the researcher's company (i.e. KPMG). Simultaneously, a 
google document platform is built up and then directly sent to the target respondents in three remaining companies. The minimum sample size is determined by applying 10 times principle (Barclay et al., 1995). As such, the researcher decided to select the minimum sample size of 250 observations.

Data analysis utilized a two-step approach as recommended by Anderson and Gerbing (1988). The first step involves the analysis of the measurement model, while the second step tests the structural relationships among latent constructs. To accomplish this objective, PLS-SEM was used as it is appropriate for complex structural model and it allows researcher to identify the key factors in the model. The methods of using PLS might be appropriate for its ability to improve the propositions by investigating in detail the relationships among variables.

\section{Analysis and findings}

Number of collected questionnaires is 256 . The male employee accounts for $52.34 \%$ while female accounts for $47.66 \%$. Among respondents, 121 employees currently work at KPMG $(47.27 \%)$, 47 employees of PwC (18.36\%), 45 employees of EY (17.58\%) and the remaining come from Deloitte (16.8\%). Most respondents (55.08\%) have from 1 to 3 years of experience, $22.27 \%$ of respondents have from 3 to 5 years of experience, from 5 to 10 years and more than 10 years take up $16.41 \%$ and $6.25 \%$, respectively. With respect to current position, most of them are staff $(46.48 \%)$, senior staff (24.61\%), Assistant/Deputy Manager (8.59\%), Manager (18.36\%) and Director and above (1.95\%). The percentage of single employee is $72.66 \%$ whereas married ones is $27.34 \%$.

Initially, the analysis of validity and reliability is performed. Composite Reliability (CR) is used to examine internal consistency. Hair et al (2014) suggests that CR value should be above 0.7, as such, all constructs are qualified for the test of internal consistency as in Table 1. Next, the convergent validity is investigated by two indicators suggested by Fornell and Larcker (1981): (i) all constructs' loading should be significant and exceed 0.7; and (ii) average variance extracted (AVE) by each construct should exceed 0.5 . As such, the results certify the convergent validity of all constructs.

Table 1: Measurement of reflective constructs

\begin{tabular}{ccccc}
\hline Constructs & No. Items & Factor loadings & CR & AVE \\
\hline EE & 3 & $0.901-0.960$ & 0.947 & 0.858 \\
CB & 4 & $0.808-0.934$ & 0.934 & 0.779 \\
CO & 6 & $0.715-0.900$ & 0.932 & 0.697 \\
PO & 6 & $0.711-0.887$ & 0.938 & 0.717 \\
SS & 5 & $0.823-0.915$ & 0.944 & 0.772 \\
LS & 4 & $0.884-0.928$ & 0.946 & 0.813 \\
OC & 4 & $0.795-0.820$ & 0.883 & 0.654 \\
EIS & 5 & $0.840-0.931$ & 0.939 & 0.754 \\
\hline
\end{tabular}

Table 2: Discriminant validity coefficients

\begin{tabular}{ccccccccccc}
\hline & Mean & SD & CB & CO & EE & EIS & LS & OC & PO & SS \\
\hline CB & 4.244 & 1.552 & $\mathbf{0 . 8 8 3}$ & & & & & & & \\
C & & & & & & & & & & \\
O & 5.120 & 1.151 & 0.422 & $\mathbf{0 . 8 3 5}$ & & & & & & \\
EE & 4.724 & 1.518 & -0.296 & -0.115 & $\mathbf{0 . 9 2 6}$ & & & & & \\
EI & & & & & & & & & \\
S & 4.516 & 1.622 & 0.484 & 0.364 & -0.373 & $\mathbf{0 . 8 6 8}$ & & & & \\
\end{tabular}




\begin{tabular}{cccccccccccc} 
LS & 4.829 & 1.350 & 0.443 & 0.499 & -0.049 & 0.423 & $\mathbf{0 . 9 0 2}$ & & & \\
O & & & & & & & & & & \\
C & 4.732 & 1.455 & 0.584 & 0.492 & -0.298 & 0.790 & 0.576 & $\mathbf{0 . 8 0 9}$ & & \\
PO & 4.990 & 1.333 & 0.489 & 0.435 & -0.101 & 0.398 & 0.431 & 0.474 & $\mathbf{0 . 8 4 7}$ & \\
SS & 4.651 & 1.284 & 0.374 & 0.514 & -0.142 & 0.428 & 0.680 & 0.497 & 0.492 & $\mathbf{0 . 8 7 9}$ \\
\hline
\end{tabular}

To assess the discriminant validity of the constructs, two approaches were used. First, the cross loadings of the indicators were examined. This finding revealed that no indicator loads are higher on an opposing construct. Second, following the Fornell and Larcker (1981) criterion, the square root of AVE for each construct exceeded the intercorrelations of the construct with the other constructs in the model (Table 2). Both analyses confirmed the discriminant validity of all constructs.

Once the construct measures are confirmed to be reliable and valid, the assessment of structural model is performed by examining predictive capabilities of the model as well as relationships among constructs. Firstly, collinearity is tested by variance inflation factor (VIF). All VIF are less than 5, showing that there is no collinearity issue, hence, the analysis could be continued. Next, model fit is examined by coefficient of determination $\left(\mathrm{R}^{2}\right)$, predictive relevance $\left(\mathrm{Q}^{2}\right)$ and effect size $\left(\mathrm{f}^{2}\right)$. The $\mathrm{R}^{2}$ indicates that predictors explain $51.4 \%$ of organizational commitment and $64.2 \%$ of employee's intention to stay. $\mathrm{Q}^{2}$ is a measure used to assess the relative predictive relevance of a predictor construct on an endogenous construct based on the blindfolding technique. $\mathrm{Q}^{2}$ more than zero for a dependent variable indicates that there is a relevant prediction power for that specific construct in the model (Chin, 2010). $\mathrm{Q}^{2}$ of organizational commitment and employee's intention to stay are 0.311 and 0.450 , hence, the model is proved to be acceptable fit and high predictive relevance. Continuously, effect size (f2) is used to measure the change of $\mathrm{R}^{2}$ value when a specified exogenous construct is omitted from the model and its effect on the exogenous latent variable. Based on the findings, compensation and benefit has no effect while organizational commitment has large effect on employee's intention to stay $\left(\mathrm{f}^{2}=0.763\right)$. Remaining variables have small effect on organizational commitment and employee's intention to stay.

From the above table, employee's intention to stay is direcly affected by emotional exhaustion and organizational commitment. Whereas except for supervisor support, all predictors are supported to influence organizatinal commitment. The indirect relationship of emotional exhaustion, compensation and benefit, promotion opportunity, co-worker relationship and leadership to employee's intention to stay are also confirmed. 


\begin{tabular}{lrrc}
\hline \multicolumn{1}{c}{ Relationship } & $\begin{array}{r}\text { Path } \\
\text { Coefficient }\end{array}$ & Indirect effect & Effect Size \\
\hline $\mathrm{EE} \rightarrow$ OC & $-0.170^{*}$ & & 0.054 \\
$\mathrm{CB} \rightarrow$ OC & $0.270^{*}$ & 0.095 \\
$\mathrm{PO} \rightarrow$ OC & $0.116^{* * *}$ & 0.018 \\
$\mathrm{CO} \rightarrow$ OC & $0.137^{* * *}$ & & 0.025 \\
$\mathrm{SS} \rightarrow$ OC & 0.036 & & 0.001 \\
$\mathrm{LS} \rightarrow$ OC & $0.305^{*}$ & & 0.093 \\
$\mathrm{EE} \rightarrow$ EIS & $-0.141^{* *}$ & $-0.127^{*}$ & 0.048 \\
$\mathrm{CB} \rightarrow$ EIS & 0.008 & $0.202^{*}$ & 0.000 \\
$\mathrm{PO} \rightarrow$ EIS & 0.033 & $0.086^{* * *}$ & 0.002 \\
$\mathrm{CO} \rightarrow$ EIS & -0.050 & $0.103^{* * *}$ & 0.004 \\
$\mathrm{SS} \rightarrow$ EIS & 0.089 & & 0.010 \\
$\mathrm{LS} \rightarrow$ EIS & -0.068 & $0.228^{*}$ & 0.006 \\
$\mathrm{OC} \rightarrow$ EIS & $0.748^{*}$ & & 0.763 \\
\hline
\end{tabular}

\section{Conclusion}

Based on the research's results, organizational commitment has a significant influence to employee's intention to stay, specifically $\beta=0.748, p<0.001$. Similarly, in the research of Chaney (1991), a positive relationship between organizational commitment and employee's intention to stay is proved. The organizational commitment itself is influenced by emotional exhaustion $(\beta=-0.170)$, compensation and benefit $(\beta=0.27)$, promotion opportunity $(\beta=0.116)$, co-worker relationship $(\beta=0.137)$ and leadership $(\beta=0.305)$. The results are proved to be consistent with previous studies stated in section 2 . The results also indicate that emotional exhaustion $(\beta=-0.141)$ has negative relationship with intention to stay. The more emotionally exhausted employees face, the more likely employees leave the firm. This relationship is also mediated by organizational commitment.

This study provides better understanding on the determinants of intention to stay of employees working at big-four auditing firms in Ho Chi Minh City. From data analysis and discussion, level of effect of each determinant can be determined. Based on that, to retain employee, the firms can select suitable strategies under limited resources. The findings show that intention to stay of an employee is significant impacted by organizational commitment and emotional exhaustion. Therefore, to increase employee's intention stay, the key is to increase positive factors and decrease negative factors impact to organizational commitment and emotional exhaustion. Organizational commitment should be focus more since its impact $(\beta=0.748)$ is more significant than emotional exhaustion $(\beta=-0.141)$. To increase organizational commitment, the researcher suggests big-four auditing companies prioritize retention strategy in descending order as: leadership, compensation and benefit, emotional exhaustion, coworker relationship and promotion opportunity. Employees view leaders as the determinant of organization development since leaders are people who decide the company's goal and value as well as business strategies. Furthermore, all employees' benefits from the companies are all finally decided by leaders. Therefore, leaders from big-four auditing companies should show more interest and care to 
their employees as an action to retain employees. Secondly, increasing compensation and benefits are also significant. The employees' contribution to the companies are returned visibly as compensation and benefits. As such, it is recommended for human resource department as well as board of management to review current compensation and benefit package and take necessary action. It is not necessary to increase in financial dimension. The companies can consider to apply appropriate benefitin-kind. Next, the companies should focus on reducing employee's emotional exhaustion from the environment by tracking workload and equally divide workload to increase their motivation along with aspiration to work. Especially, during peak season, the companies should take more care on health condition by supplying foods, exercise activities... to help employee reduce emotional exhaustion. In addition, the companies should consider impacts from co-worker relationship. Increasing teamwork to make friendly working environment will help increase organizational commitment. Finally, promotion opportunity is also important. When chances of promotion are available and fair, they will encourage employee to contribute and stick to the organization.

\section{Limitations and Future Research}

Although this study is practically conducted, it still contains some limitations that should be ameliorated in future researches. Firstly, due to the resource constrains, some limited factors are used to investigate the influence to employee's intention to stay. In fact, there might be many other factors contributing to employee's intention to stay. Future studies can extend to other factors as well as further analyze impact of demographic factors such as gender, age... Secondly, the research is performed based on 256 respondents from big-four companies in Ho Chi Minh City by convenient method. The sample size might not symbolize the whole population. In addition, $55.08 \%$ of the collected questionnaires are from employee working from one to three years. The short time of working experience can limit their judgment on intention to stay. Moreover, employees with higher year of experience should be focused more owing to the fact that the senior employees can contribute more to the companies. Finally, the findings might not be accurately since the respondents' attitude might change over the time with the changes of human resource policies along with labor market conditions. Furthermore, the research only focus on the general concept of employee's intention to stay of four biggest auditing companies in Ho Chi Minh City but does not perform comparison among them. Since each company have their own culture and environment, the differentiation of employee's intention to stay will be an interesting topic for future researches.

\section{References}

Alarcon GM (2011). A meta-analysis of burnout with job demands, resources and attitudes. Journal of Vocational Behavior, 29: 549-562.

Amiria M, Khosravib A, and Mokhtari AA (2010). Job Satisfaction and Its Influential Factors, Journal of Research in Health Sciences, 10(1): 42-46.

Azeem SM (2010). Personality hardiness, job involvement and job burnout among teachers. International Journal of Vocational and Technical Education, 2(3): 36-40.

Beardwell $J$ and Thompson A (2014). Human resource management: a contemporary approach. Pearson Education.

Blau PM (1964). Exchange and power in social life. Transaction Publishers.

Boles JS, Johnston MW, and Hair JF (1997). Role stress, work-family conflict and emotional exhaustion: Inter-relationships and effects on some work-related consequences. Journal of Personal Selling \& Sales Management, 17: 17-28.

Bunderson JS (2001). How work ideologies shape the psychological contracts of professional employees: Doctors' responses to perceived breach. Journal of Organizational Behavior,22(7): 717-741.

Casper WJ, Harris C, Taylor-Bianco A, and Wayne JH (2011). Work-family conflict, perceived supervisor support and organizational commitment among Brazilian professionals. Journal of Vocational Behavior, 79(3): 640-652.

Cassel CM, Hackl P, and Westlund AH (2000). On measurement of intangible assets: a study of robustness of partial least squares. Total Quality Management, 11, 897-907.

Chaney TG (1991). Job satisfaction, organizational commitment, and intent to stay among United States Air Force certified registered nurse anesthetists (No. AFIT/CI/CIA-91-021). 
Chin WW (2010). How to write up and report PLS analyses. In Handbook of partial least squares: Concepts, methods and applications in marketing and related fields (pp. 665-690). Berlin: Springer.

Coyle-Shapiro J and Kessler I (2000). Consequence of the psychological contract for the employment relationship: A large scale survey. Journal of Management Studies, 37(7): 903-930.

Gerbing DW and Anderson JC (1988). An updated paradigm for scale development incorporating unidimensionality and its assessment. Journal of Marketing Research, 1: 186-192.

Hair JF, Hult GM, Ringle CM and Sarstedt M (2014). A primer on partial least squares structural equation modeling (PLS-SEM). SAGE Publications, Inc.

Jackson SE and Maslach C (1982). After-effects of job-related stress: Families as victims. Journal of Organizational Behavior, 3(1): 63-77.

Johari JO, Yean TF, Adnan NA, Yahya, KK and Ahmad, MN (2012). Promoting employee intention to stay: Do human resource management practices matter. International Journal Economics and Management, 6(2): 396-416.

Maslach C, Schaufeli WB, and Leiter MP (2001). Job Burnout. Annual Review of Psychology, 52: 397-422.

McNeese-Smith D (1995). Job Satisfaction, Productivity, and Organizational Commitment: The Result of Leadership. Journal of Nursing Administration, 25(9): 17-26.

Miller JG and Wheeler KG (1992). Unraveling the mysteries of gender differences in intentions to leave the organization. Journal of Organizational Behavior, 13(5): 465-478.

Mossholder KW, Settoon RP, and Henagan SC (2005). A relational perspective on turnover: Examining structural, attitudinal, and behavioral predictors. Academy of Management Journal, 48(4): 607-618.

Mossholder KW, Settoon RP, and Henagan SC (2005). A relational perspective on turnover: Examining structural, attitudinal, and behavioral predictors. Academy of Management Journal, 48(4): 607-618.

Mustapha N, Ahmad A, Uli J and Iis K (2010). Job characteristics as antecedents of intention to stay among single mothers in Malaysia. International Journal of Business and Social Science, 1(3).

Nasyira MN, Othman $M$ and Ghazali $H$ (2011). Predictors of intention to stay for employees of casual dining restaurant in klang valley area, international food organisations in Malaysia, International Journal of Business, Management and Social Sciences, 2 (1): 24-32.

Siew PL, Chitpakdee, $B$ and Chontawan $R$ (2011). Factors predicting organizational commitment among nurses in state hospitals, Malaysia. The International Medical Journal of Malaysia, 10(2).

Wan H, Sulaiman $M$ and Omar A (2012). Procedural justice in promotion decision of managerial staff in Malaysia. Asia Pacific Business Review, 18(1): 99-121. 